\title{
Review of Dibrachys Förster from China (Hymenoptera, Chalcidoidea, Pteromalidae)
}

\author{
Tian-yang Jiao ${ }^{1,2}$, Qin-ying Yao',3, Hui Xiao' \\ I Key Laboratory of Zoological Systematics and Evolution, Institute of Zoology, Chinese Academy of Sciences, \\ Beijing, 100101, P. R. China 2 College of Life Sciences, University of Chinese Academy of Sciences, Beijing, \\ 100101, P. R. China 3 College of Life Science and Technology, Hebei University, Baoding, 071002, P. R. China \\ Corresponding author: Hui Xiao (xiaoh@ioz.ac.cn) \\ Academic editor:J. Fernandez-Triana | Received30 November2016 | Accepted 11 January 2017 | Published 14February 2017 \\ http://zoobank.org/11FEFBEC-24EA-4AD6-BF7E-E01809E4112D \\ Citation: Jiao T-y, Yao Q-y, Xiao H (2017) Review of Dibrachys Förster from China (Hymenoptera, Chalcidoidea, \\ Pteromalidae). ZooKeys 656: 123-149. https://doi.org/10.3897/zookeys.656.11373
}

\begin{abstract}
Twelve species of Dibrachys Förster are studied from China, of which four new species, D. golmudica Jiao \& Xiao, sp. n., D. kunmingica Jiao \& Xiao, sp. n., D. liaoi Jiao \& Xiao, sp. n. and D. qinghaiensis Jiao \& Xiao, sp. n., and four newly recorded species, D. braconidis (Ferrière \& Faure), D. confusus (Girault), $D$. hians Bouček and D. maculipennis Szelényi, are reported. A key to Chinese Dibrachys and illustrations of external features of the species are provided.
\end{abstract}

\section{Keywords}

China Mainland, Dibrachys, key, new species, new record, Pteromalidae, taxonomy

\section{Introduction}

Dibrachys was erected by Förster in 1856, but without any species included in the genus. Thomson (1878) subsequently designated Pteromalus boucheanus Ratzeburg, 1844 as the type species and listed Pteromalus cavus Walker, 1835 as a synonym. Although the type material of P. boucheanus is lost (Graham 1969), Thomson's work was accepted by the majority of later researchers. Graham (1969) designated a lectotype for 
P. cavus and suggested that, failing the discovery of the type material of $P$. boucheanus, the lectotype of $P$. cavus might conveniently be made also the neotype of $P$. boucheanus because the two were supposed to be identical. However, Peters and Baur (2011) designated a different specimen as lectotype as part of their review of the Dibrachys cavus species complex, in which they treated Dibrachys cavus as a junior synonym of Dibrachys microgastri (Bouché, 1834). Consequently, D. microgastri (Bouché) is the senior synonym of both $D$. boucheanus (Ratzeburg) and D. cavus (Walker).

Based on differences in mandibular formula and fore wing marginal fringe, Bouček (1965) divided the genus into two subgenera Dibrachys Förster s. str. and D. (Allodibrachys Bouček). Nineteen valid species of Dibrachys are recognized, of which 13 are known from the Palearctic region, 8 from the Nearctic region, 4 from the Oriental region, 1 from the Australasian region, 1 from the Afrotropical region and 2 from the Neotropical region (Noyes 2016). Most species are parasitoids of insect pests, and play an important role in biological control, with 372 different host species being reported for Dibrachys (Grissell 1974; Noyes 2016), including species of Lepidoptera, Hymenoptera, Diptera, Coleoptera, Dermaptera, Hemiptera, Neuroptera, Strepsiptera, and several species of Arachnida (Araneidae and Philodromidae). However, as Graham (1969) noted, almost all the host records are associated with $D$. cavus.

Only four species of Dibrachys have previously been recorded in China (Liao 1987; Yang 1996). In this study 12 species are identified from China, including four new species (D. golmudica Jiao \& Xiao, sp. n., D. kunmingica Jiao \& Xiao, sp. n., D. liaoi Jiao \& Xiao, sp. n., D. qinghaiensis Jiao \& Xiao, sp. n.) and four newly recorded species (D. braconidis (Ferrière \& Faure), Dibrachys confusus (Girault), D. hians Bouček, and D. maculipennis Szelényi).

\section{Material and methods}

A total of 943 specimens was examined from the museum of Institute of Zoology, the Chinese Academy of Sciences (IZCAS). All material from our own collection was swept and preserved in 75\% ethanol. Specimens were subsequently air dried, pointmounted and examined with a Nikon SMZ1500 stereomicroscope. Photographs were taken using a Nikon Multizoom AZ100 system, and the plates were compiled using Adobe Photoshop CS3 software. In addition, the author had examined specimens of Dibrachys deposited in the National History Museum, London, the Naturalis, Leiden and the Bavarian State Collections of Zoology in April, 2002.

Morphological terminology mostly follows that of Graham (1969), Bouček (1988) and Gibson (1997). All specimens were examined and identified using the keys of Graham (1969), Grissell (1974), Doganlar (1987), Yang (1996), Zerova et al (1992) and Peters and Baur (2011). Every new species is described based on the holotype specimen, other species are described basing on the examined material available to us. Body length excludes the ovipositor sheaths and is measured in millimeters $(\mathrm{mm})$; other measurements are given as ratios. 
Abbreviations of morphological terms used are:

Fu $\mathbf{u}_{\mathrm{n}} \quad$ funicular segment number;

POL posterior ocellar distance;

OOL ocellocular distance;

$\mathbf{G t}_{\mathbf{n}} \quad$ gastral tergum number.

\section{Taxonomy}

\section{Key to species}

$1 \quad$ Left mandible with three teeth and right mandible with four teeth (Fig. 6); fore wing with marginal fringe except between marginal vein and wing apex; occipital carina transverse, closer to foramen than vertex; gaster mostly ovate (Figs 1,5), slightly longer than broad

D. (Allodibrachys)...2

- $\quad$ Both mandibles with four teeth (Fig. 21); fore wing without marginal fringe; occipital carina curving, closer to vertex than foramen; gaster spindle-shaped (Figs 15, 23, 33, 38), distinctly longer than broad

D. (Dibrachys)...6 Head in frontal view with gena almost straight and with lower angle of gena protruding beyond clypeal margin (Fig. 3).

D. hians

- Head in frontal view with gena evenly curved and with lower angle of gena not exceeding clypeal margin (Figs 6, 12) Stigmal vein longer than postmarginal vein; gaster 1.5 times as long as broad

D. koraiensis

- $\quad$ Stigmal vein shorter than or at most as long as postmarginal vein; gaster at most 1.3 times as long as broad.................................................................... 4 Lower margin of clypeus not protruded, slightly emarginate in middle and without tooth (Fig. 6); head in dorsal view with POL 1.33 times as long as OOL D. kojimae

- Lower margin slightly protruded, emarginate in middle and with two obtuse teeth; head in dorsal view with POL more than 1.5 times as long as OOL .... 5 Marginal vein 1.5 times as long as stigmal vein; propodeum with plica complete and median carina only distinct basally D. yunnanensis Marginal vein 1.91 times as long as stigmal vein; propodeum with plica only conspicuous basally, median carina absent D. kunmingica sp. $\mathrm{n}$. Antennae with three anelli; postmarginal vein very shorter than stigmal vein, at most half length of stigmal vein D. golmudica sp. $\mathbf{n}$. Antennae with two anelli; postmarginal vein longer or slightly shorter than stigmal vein Lower margin of clypeus broadly emarginate, without tooth; gaster 1.37 times as long as broad D. braconidis

- $\quad$ Lower margin of clypeus slightly protruding, emarginate in middle and with two blunt or sharp teeth; gaster at least 1.8 times as long as broad 
8 Antennal insertion slightly above lower ocular line, antennal scape reaching lower margin of anterior ocellus................................................................... 9

- $\quad$ Antennal insertion place on lower ocular line, antennal scape not reaching lower margin of anterior ocellus..............................................................11

9 Fore wing with a yellowish-brown infumation behind marginal vein; propodeum with incomplete median carina; stigmal vein slightly longer than postmarginal vein; gaster slightly broader than thorax width D. maculipennis

- $\quad$ Fore wing immaculate, without any infumation; propodeum with complete median carina; stigmal vein as long as postmarginal vein; gaster narrower than thorax width

10 Antennal scape as long as eye height; head in frontal view 1.27 times as wide as high

D. qinghaiensis sp. $\mathrm{n}$.

- $\quad$ Antennal scape distinctly shorter than eye height; head in frontal view 1.15 times as wide as high

D. confusus

11 Lower margin of clypeus emarginate in middle and with two sharp teeth (Fig. 31); antennae with $\mathrm{Fu}_{1}$ to $\mathrm{Fu}_{4}$ slightly longer than its broad; head in dorsal view 1.8 times as wide as long; gaster 1.8 times as long as broad......

D. liaoi sp. $\mathrm{n}$.

- $\quad$ Lower margin of clypeus emarginate in middle and with two blunt teeth (Figs 40, 45 ); antennae with $\mathrm{Fu}_{1}$ to $\mathrm{Fu}_{4}$ quadrate; head in dorsal view 2 times as wide as long; gaster 2 times as long as broad

D. microgastri

\section{Dibrachys Förster, 1856}

Dibrachys Förster, 1856: 65. Type-species: Pteromalus boucheanus Ratzeburg, designated by Thomson 1878: 47 (= Diplolepis microgastri Bouché, 1834: 168).

Dibrachys Förster: Dalla Torre 1898: 155; Graham 1969: 804-814; Wallace 1973: 175-176; Bouček 1993: 1259; Yang 1996: 196-201, 323-324.

Coelopisthoidea Gahan, 1913: 178-183. Type-species: Coelopisthoidea cladiae Gahan, 1913: 178-183. Synonymized by Girault 1916b: 408; Bouček 1988: 434.

Diagnosis. Body dark green. Head in frontal view round; antennal insertion placed on lower ocular line and face not protuberant at antennal insertion; antennal formula 11263 (rarely 11353); lower margin of clypeus with two sinuate teeth; both mandibles with four teeth or right mandible with four teeth and left mandible with three teeth; head in dorsal view with occiput margined by blunt or sharp, transverse ridge. Mesosoma slightly convex; pronotal collar not margined or slightly carinate medially; notauli incomplete and inconspicuous; scutellum without frenal groove; propodeum with plica complete, median carina developed or not. Fore wing without marginal fringe or at least bare between postmarginal vein and wing apex; postmarginal vein short, only inconspicuously longer than stigmal vein. Hind tibia with one spur. Gaster ovate. 
Distribution. Widespread world-wide distribution, see Noyes (2016). China: Heilongjiang, Jilin, Liaoning, Inner Mongolia, Beijing, Hebei, Shanxi, Shandong, Henan, Shaanxi, Ningxia, Gansu, Qinghai, Xinjiang, Jiangsu, Shanghai, Anhui, Zhejiang, Hubei, Jiangxi, Hunan, Guangxi, Sichuan, Guizhou, Yunnan and Tibet.

\section{Descriptions of species}

\section{Dibrachys (Allodibrachys) Bouček}

Dibrachys sgen. Allodibrachys Bouček, 1965: 30. Type-species : Dibrachys hians Bouček, by original designation.

Diagnosis. The subgenus have the left mandible with three teeth and right mandible with four teeth; occipital carina transverse, closer to foramen than vertex; fore wing with marginal fringe except between marginal vein and wing apex; gaster mostly ovate, slightly longer than broad.

\section{Dibrachys hians Bouček, 1965, new record to China}

Figs 1-4

Dibrachys (Allodibrachys) bians Bouček, 1965: 28.

Diagnosis. Body length 1.6-2.0 mm (Figs 1, 2). Head in frontal view (Fig. 3) $1.32 \times$ as wide as high; antennal scrobe shallow, extending upwards and not reaching anterior ocellus; antennal insertion placed on lower ocular line; clypeus with longitudinal striation; lower margin of clypeus not protruded, emarginate in middle, and without tooth; gena almost straight, lower angle of gena protruding beyond clypeal margin. Antenna (Fig. 4) with scape shorter than eye height ( $0.79 \times)$, not reaching anterior ocellus; length of pedicel and flagellum combined less than head width (0.67x); anelli transverse; each funicular segment subquarate; clava slightly clavate. Head in dorsal view with width $2 \times$ length; eye length $2 \times$ temple length; POL $2 \times$ OOL. Mesosoma $1.37 \times$ as long as broad, mid lobe of mesoscutum with regular sculpture. Propodeum with complete median carina and incomplete plica. Fore wing with marginal vein $1.8 \times$ as long as postmarginal vein; postmarginal vein as long as stigmal vein. Gaster $1.25 \times$ as long as broad, slightly broader than thorax width.

Material examined. China: 3q, Heilongjiang: Yichun, 13.VII.1962, ex. Tachinidae sp. on Ptycholomoides aeriferanus Herrich-Schaffer, leg. Ding-Xi Liao; $1 \hat{O}^{\widehat{T}}$, 1우, Heilongjiang: Dailing, 29.VI.1962, ex. Tachinidae sp. on Ptycholomoides aeriferanus Herrich-Schaffer; 19, Jilin: Dunhua, 25.VI.1990; 10, 2q, Beijing: Yanqing, 19.VII.1982, ex. Curculionidae sp. on elm, leg. Ding-Xi Liao. 

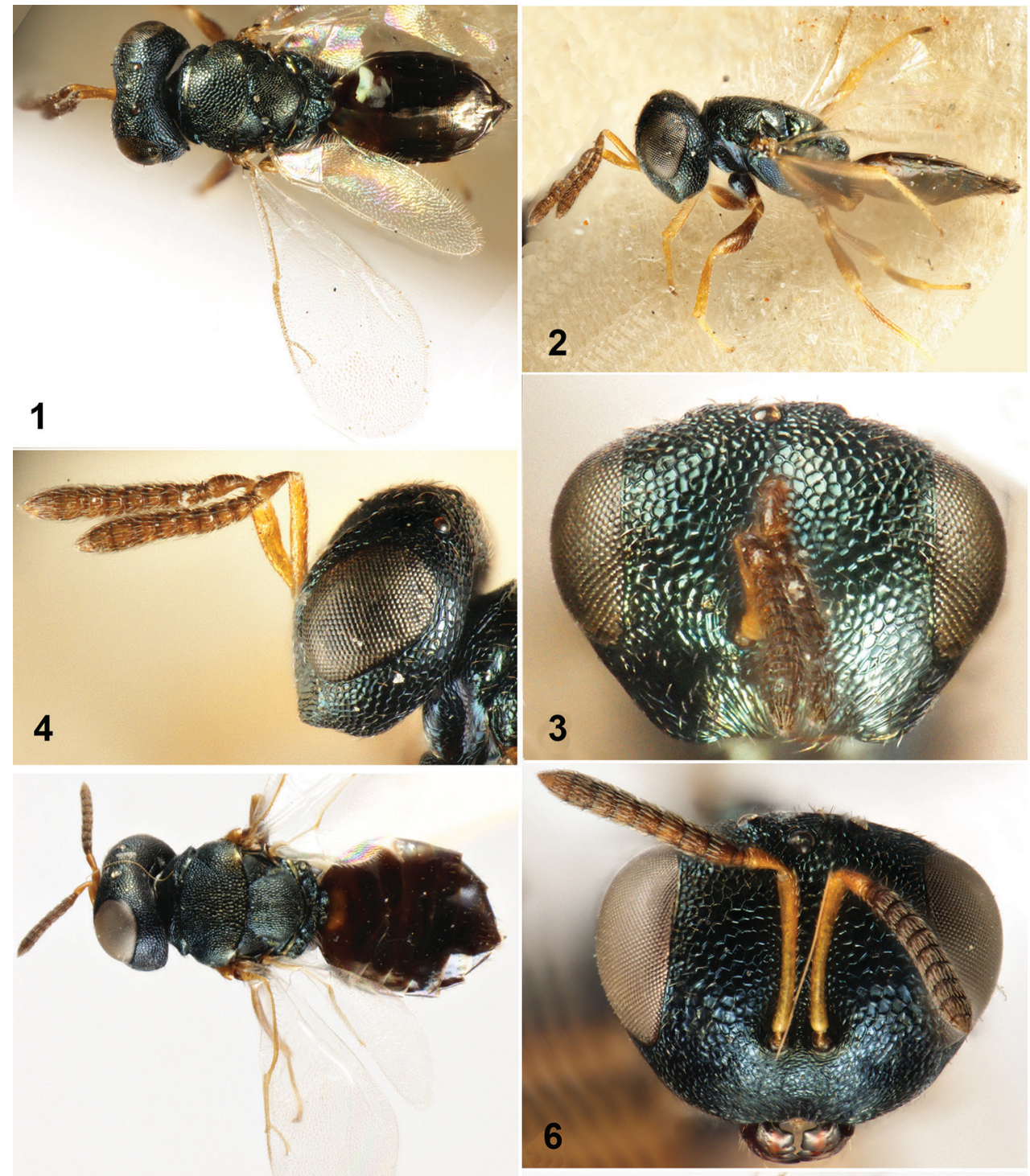

\section{5}
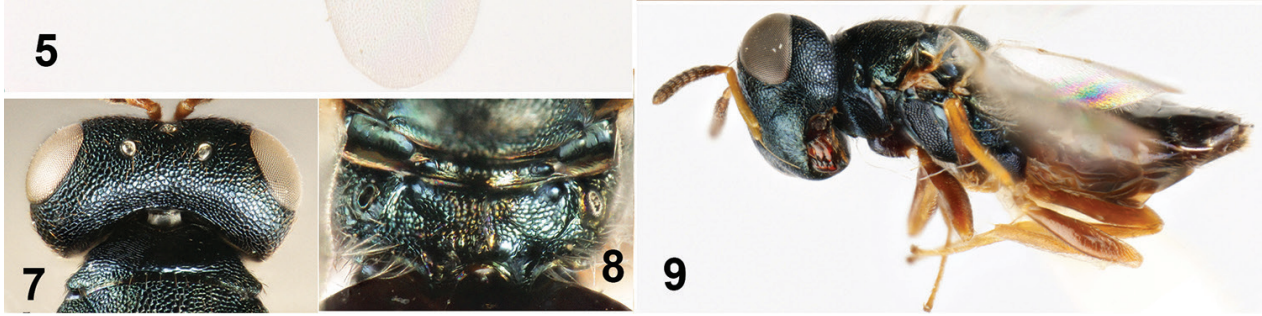

Figures I-9. I-4 Dibrachys hians Bouček, 1965. I Body in dorsal view 2 Body in lateral view 3 Head in frontal view 4 Head in lateral view 5-9 Dibrachys kojimae (Ishii, 1916) 5 Body in dorsal view 6 Head in frontal view $\mathbf{7}$ Head in dorsal view 8 Propodeum 9 Body in lateral view. 
Hosts. Trematerra (1988) reported Pyralis farinalis L (Lepidoptera: Pyralidae). as a host and here we record Curculionidae sp. on elm, Tachinidae sp. on Ptycholomoides aeriferanus Herrich-Schaffer (Lepidoptera: Tortricidae), and Tachinidae sp. on Laspeyresia grunertiana (Ratzeburg) (Lepidoptera: Noctuoidea).

Distribution. China (Heilongjiang, Jilin, Beijing); Palearctic and Nearctic regions.

\section{Dibrachys kojimae (Ishii, 1938)}

Figs 5-9

Euterus kojimae Ishii, 1938: 100.

Dibrachys kojimae (Ishii): Kamijo 1982: 74.

Diagnosis. Body length 2.5-3.2 mm (Figs 5, 9). Head in frontal view (Fig. 6) 1.31× as wide as high; sculpture on lateral area of antennal scrobe distinctly larger than on vertex and face; lower margin of clypeus not protruded, slightly emarginate in median; gena evenly curved, lower angle of gena not exceeding clypeal margin. Antenna with scape shorter than eye height $(0.81 \times)$; length of pedicel and flagellum combined less than head width $(0.94 \times)$; anelli transverse and second anellus longer than first anellus; $\mathrm{Fu}_{1}-\mathrm{Fu}_{3}$ slightly long than wide, $\mathrm{Fu}_{4}-\mathrm{Fu}_{6}$ subquadrate. Head in dorsal view (Fig. 7) $2 \times$ as wide as long; eye length $1.67 \times$ temple length, POL 1.33× OOL. Mesosoma $1.32 \times$ as long as broad; with regular sculpture. Propodeum (Fig. 8) with incomplete median carina and complete plica. Fore wing with submarginal vein $2.3 \times$ as long as marginal vein; marginal vein $1.6 \times$ as long as postmarginal vein, $1.8 \times$ as long as stigma vein; stigmal vein slightly shorter than postmarginal vein $(0.9 \times)$. Gaster $1.2 \times$ as long as broad, slightly broader than thorax width.

Material examined. China: $2{ }^{\lambda}$, 16우, Beijing: Miyun Reservoir, 10-20.VII.1983, ex. pupae of Dendrolimus tabulaeformis Tsai et Liu, leg. Ju-Wen Wu; 7으, Henan: Fangchen, Dalai, VIII. 1983, ex. pupae of Dendrolimus tabulaeformis Tsai et Liu, leg. De-Long Shui; $1{ }^{\lambda}, 11$, Anhui: Dongzhi, 1983, ex. pupae of Dendrolimus, leg. DingXi Liao; 2へ, 3 , Anhui: Dongzhi, 7.V.1983, ex. Dendrolimus punctatus Walker, leg. Ding-Xi Liao; 39 , Anhui: Qianshan, Tianzhu Mountain, 4.IX.1976, ex. pupae of Dendrolimus, leg. Tao-Qian Hou; 19 , Hubei: Wuhan, 25.VI.1980, ex. Dendrolimus punctatus (Walker), leg. Tao-Qian Hou; 4ㅇ, Hunan, 25.X.1979, ex. pupae of Pieris brassicae L., leg. Ding-Xi Liao; 1 ${ }^{\lambda}, 7$, , Hunan: Chengbu, 16. VIII.1986, ex. pupae of Dendrolimus kikuchii Matsumura, leg. Zheng-Mao Li; $10{ }^{\lambda}$, 15우, Hunan: Daoxian, 29.XII.1979, ex. eggs of Lebeda nobilis Walker, leg. Ding-Xi Liao; 10, 5우, Hunan: Daoxian, 12.XI.1973, ex. eggs of Lebeda nobilis Walker, leg. Xin-Wang Tong; 2 , Guangxi: Nanning, VI.1975, ex. Eggs of Dendrolimus, leg. Lin Wei; 2q, Guizhou: Anshun, 25.X.1980, ex. pupae of Dendrolimus houi Lajonquiere, leg. Jin-Rong Zhou; 6q, Yunnan: Baoshan, 21.v.1975, ex. Dendrolimus, leg. Ding-xi Liao; 1q, Tibet: Mêdog, 1100m, 26.I.1983, leg. Yin-Heng Han. 
Hosts. Kamijo (1982) reported Dendrolimus spectabilis Butler (Lepidoptera: Lasiocampidae) as a host and here we report Dendrolimus tabulaeformis Tsai et Liu, pupae/eggs of Dendrolimus, Dendrolimus punctatus (Walker), Dendrolimus kikuchii Matsumura, Dendrolimus houi Lajonquiere, Lebeda nobilis Walker (Lepidoptera: Lasiocampidae) and Pieris brassicae L. (Lepidoptera: Pieridae).

Distribution. China (Beijing, Anhui, Jiangxi, Henan, Hunan, Guangxi, Guizhou, Yunnan, Tibet); Japan.

\section{Dibrachys koraiensis Yang, 1996}

Dibrachys koraiensis Yang, 1996: 197-199, 323.

Diagnosis. Body length 2.5-2.7 mm; gaster long ovate. Head in frontal view 1.25x as wide as high; antennal scrobe extending upwards and reaching anterior ocellus; lower face slightly convex; antennal insertion placed on lower ocular line; clypeus with longitudinal striation and lower margin slightly protruded, emarginate, and with two blunt teeth; lower angle of gena not exceeding clypeal margin. Antennal scape slightly shorter than eye height $(0.87 x)$; length of pedicel and flagellum shorter than head width $(0.8 \times)$; anelli transverse; $\mathrm{Fu}_{1}$ and $\mathrm{Fu}_{2}$ slightly longer than broad, $\mathrm{Fu}_{3}$ and $\mathrm{Fu}_{4}$ quadrate, $\mathrm{Fu}_{4}$ and $\mathrm{Fu}_{6}$ slightly transverse. Head in dorsal view $1.88 \times$ as wide as long; eye length $2 \times$ temple length; POL $1.5 \times$ OOL. Mesosoma $1.7 \times$ as long as broad, mid lobe of mesoscutum with relatively coarse sculpture. Propodeum with complete plica and indistinct median carina. Fore wing length $2.2 \times$ width; submarginal vein $2 \times$ as long as marginal vein; marginal vein $2.53 \times$ as long as postmarginal vein, $2.13 \times$ as long as stigma vein; stigmal vein slightly longer than postmarginal vein $(1.15 \times)$. Gaster $1.5 \times$ as long as broad, distinctly broader than thorax width $(1.21 \times)$.

Material examined. China: 19 , Heilongjiang: Yichun, 3.VII.1972, leg. Ding-xi Liao; 1 , , Heilongjiang: Hailin, VI.1975, leg. Gui-you Zhang.

Hosts. Yang (1996) reported this species as reared from the pupae of some chalcid collected from tunnels in Picea koraiensis Nakai (Pinales: Pinaceae) built by the wood pest Orthotomicus golovjankoi Pjatnitzky (Coleoptera: Curculionidae), the possible host.

Distribution. China (Heilongjiang).

\section{Dibrachys kunmingica Jiao \& Xiao, sp. n.}

http://zoobank.org/DC6570D7-7010-4813-89D4-570403E3A730

Figs 10-14

Diagnosis. The species belongs to subgenus Allodibrachys, and similar to D. yunnanensis Yang has the lower angle of the gena not exceeding the clypeal margin, and the stigmal vein slightly shorter than the postmarginal vein. The main differences are: 
marginal vein $2 x$ as long as stigmal vein; propodeum with plica indistinct, only conspicuous basally; median carina absent.

Description. Holotype. Female. Body (Figs 10, 11) length $2.5 \mathrm{~mm}$. Head and mesosoma dark green, with metallic reflection; gaster brown with metallic reflection basally. Antenna brown except pedicel and scape yellowish brown; legs light brown except coxae brown; fore wing hyaline, slightly infumate, wing venation yellowish-brown.

Head in frontal view (Fig. 12), width 1.29× height; frons with irregular reticulation, lower face curved ventrally; eye height $0.68 \times$ head height, inner margin of eyes slightly converging upwards, separated by $1.24 \times$ their height; antennal scrope deep, not reaching anterior ocellus; reticulation in antennal scrobe smaller than that on parascrobe. Antennal insertion slightly above lower ocular line, distance from upper margin of antennal torulus to lower margin of anterior ocellus $2 \times$ distance from lower margin of antennal torulus to clypeal margin; clypeus with dense longitudinal striation; clypeal margin slightly protruded, emarginate in the middle and with two blunt teeth, median margin concave, as a small, smooth, triangular depression; gena plump, oral fossa $0.48 \times$ as wide as head. Head in lateral view with malar sulcus inconspicuous, eye height $2.2 \times$ malar space. Antennal scape length $0.83 \times$ eye height, not reaching anterior ocellus; pedicel in lateral view $2.5 \times$ as long as broad; both anelli transverse. Head in dorsal view (Fig. 13), head $2 \times$ as wide as long; vertex convex, with regular reticulation denser than that on frons, posterior part sharply sloped down; eye length $2 \times$ temple length; POL $1.6 \times$ OOL.

Head $1.19 \times$ as broad as thorax. Mesosoma $1.37 \times$ as long as broad. Propodeum with short collar, collar subhorizontal and not margined, posterior margin smooth. Mesoscutum $2 \times$ as broad as long, reticulation on posterior area bigger than that on anterior area. Scutellum slightly convex medially, width $1.22 \times$ length, frenal line absent; reticulation shallower than that on mesoscutum posteriorly. Median length of propodeum half that of scutellum; median area flat, with deep, fine, dense reticulation; median carina absent; plica incomplete, visible anteriorly; plicae separated by $1.68 \times$ median length of propodeum; short nucha hemispheric and smooth; spiracles elongate, $2 \times$ as long as broad, separated from hind margin of metanotum by width of spiracle. Fore wing (Fig. 14) 2.36x as long as broad; without fringe from postmarginal vein to distal margin; hind wing with marginal fringe; basal vein and basal cell bare, speculum only extending to base of marginal vein; upper surface of costal cell bare, lower surface with one compact row of setae and distal 1/3 with one row of short setae and some scattered setae; submarginal vein $2 \times$ as long as marginal vein; marginal vein $1.91 \times$ as long as postmarginal vein, $2 \times$ as long as stigma vein; stigmal vein slightly shorter than postmarginal vein $(0.96 \times)$; stigmal vein curved.

Petiole quadrate, as long as broad. Gaster (Fig. 10) ovate, $1.2 \times$ as long as broad, width $1.06 \times$ thorax width, length $0.94 \times$ mesosoma length; $\mathrm{Gt}_{1}$ covering $0.42 \times$ length of gaster, posterior margin of $\mathrm{Gt}_{1}$ cambered, without distinct fovea in the middle; following tergites with posterior margin straight; tergites coriaceous.

Material examined. Holotype. $O$, China: Yunnan: Kunming, $25.94^{\circ} \mathrm{N}, 102.42^{\circ} \mathrm{E}$, IV.1954, leg. Ding-Xi Liao. Paratype. $1 q$, same data as holotype. 


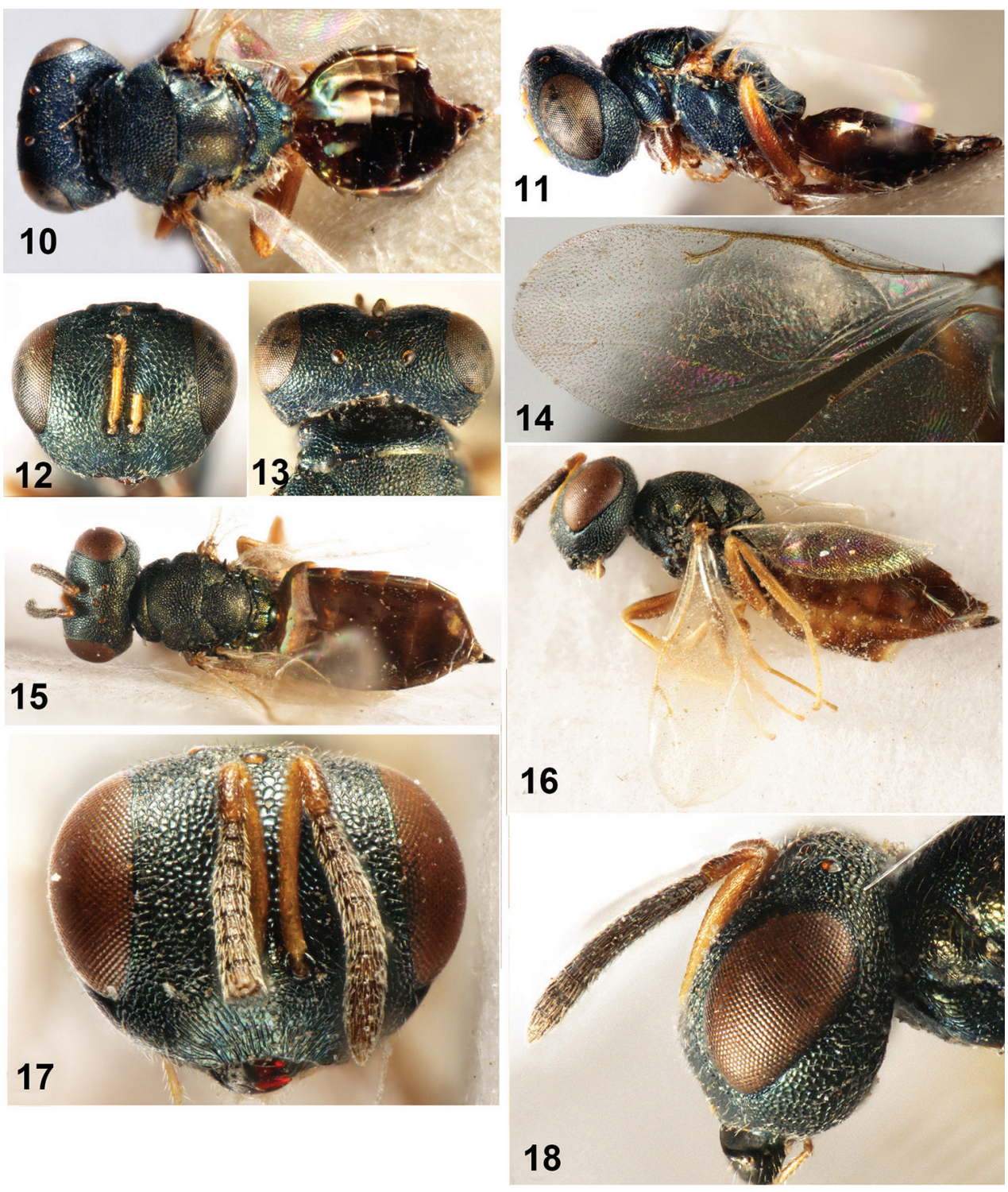

Figures I0-I 8. I0-I4 Dibrachys kunmingica sp. n., female holotype I0 Body in dorsal view II Body in lateral view $\mathbf{1} \mathbf{2}$ Head in frontal view $\mathbf{1 3}$ Head in dorsal view $1 \mathbf{4}$ Fore wing 15-18 Dibrachys braconidis (Ferrière et Faure, 1925). $\mathbf{1 5}$ Body in dorsal view $\mathbf{1 6}$ Body in lateral view $\mathbf{1 7}$ Head in frontal view 18 Head in lateral view.

Etymology. Named after the location of the type material.

Hosts. Unknown.

Distribution. China (Yunnan). 


\section{Dibrachys yunnanensis Yang, 1996}

Dibrachys yunnanensis Yang, 1996: 199-201, 324.

Diagnosis. Body squat, length $2.0-2.4 \mathrm{~mm}$. Head in front view $1.3 \times$ as wide as high; antennal scrobe shallow, extending upwards and reaching anterior ocellus; antennal insertion placed on the lower ocular line; clypeus with longitudinal sculpture; lower margin of clypeus slightly protruded, median emarginate and with 2 sinuate teeth; gena evenly curved, lower angle of gena not exceeding clypeal margin. Antennal scape slightly shorter than eye height, length of flagellum and pedicel combined less than head width $(0.74 \times)$; pedicel in lateral view $2.2 \times$ as long as broad; both anelli transverse; $\mathrm{Fu}_{1}$ and $\mathrm{Fu}_{5}$ quadrate, $\mathrm{Fu}_{6}$ distinctly transverse. Head in dorsal view, $1.9 \times$ as wide as long, eye length $1.79 \times$ temple length; POL $1.78 \times$ OOL. Mesosoma $1.5 \times$ as long as broad, mid lobe of mesoscutum with regular sculpture. Propodeum with plicae complete, median carina distinct on base part. Fore wing with submarginal vein more than $2 \times$ as long as marginal vein, marginal vein $1.5 \times$ as long as postmarginal vein, stigmal vein as long as postmarginal vein. Gaster $1.3 \times$ as long as broad, as broad as thorax width.

Material examined. China: 1 , Yunnan: Nanjian, 2.VI.1980, leg. Ding-Xi Liao.

Hosts. This species parasitized on larvae and pupae of Tomicus piniperda L. (Coleoptera: Curculionidae) which harmful to Pinus yunnanensis (Pinales: Pinaceae) (Yang 1996).

Distribution. China (Yunnan).

\section{Dibrachys (Dibrachys) Förster}

Diagnosis. Both mandibles with four teeth; occipital carina curving, closer to vertex than foramen; fore wing without marginal fringe; gaster spindle-shaped, distinctly longer than broad.

\section{Dibrachys braconidis (Ferrière \& Faure, 1925), new record to China}

Figs 15-18

Homoporus luniger braconidis Ferrière \& Faure, 1925, 11: 226.

Dibrachys braconidis (Ferrière \& Faure): Bouček 1965: 30; Viggiani 1968: 112-115.

Diagnosis. Body slender, length 2.0-2.9 mm (Figs 15, 16). Head in frontal view, $1.3 \times$ as wide as high; antennal scrobe extending to anterior ocellus; antennal insertion slightly above lower ocular line; lower face at least slightly convex; clypeus with longitudinal striation, lower margin of clypeus not protruding (Figs 17, 18), without tooth. Antennal scape slightly shorter than eye height, length of pedicel and flagellum shorter than head width $(0.8 \times)$; $\mathrm{Fu}_{1}$ to $\mathrm{Fu}_{3}$ slightly longer than broad, $\mathrm{Fu}_{4}$ to $\mathrm{Fu}_{6}$ 
quadrate. Head in dorsal view, $1.9 \times$ as wide as long; eye length $2 \times$ temple length; POL 1.44x OOL. Mesosoma $1.37 \times$ as long as broad. Propodeum with complete median carina and plicae. Fore wing $2.33 \times$ as long as broad; submarginal vein $2.24 \times$ as long as marginal vein; marginal vein $1.9 \times$ as long as postmarginal vein; stigmal vein as long as postmarginal vein. Gaster $1.37 \times$ as long as broad, $1.27 \times$ as broad as thorax width.

Material examined. China: 30^̃, 29ㅇ, Sichuan: Xichang, V.1992, ex. Neodiprion xiangyunicus Xiao et Zhou, leg. Zhen Zhang; 1일 Yunnan: Nanjian, 2.VI.1980; Yunnan: Kunming, 13.VII.1977, ex. pupae of Diprioninae, leg. Jing-liang Qi; 2 , Yunnan: Kunming, XII.1988, leg. Hong-ming Yang; 1엉 Tibet: Chamdo, 3400m, 15.VIII.2001, leg. Chao-dong Zhu.

Hosts. The species mainly parasitizes Luffia ferchaultella, and Luffia lapidella (Lepidoptera: Psychidae) and Apanteles glomeratus (L.) (Hymenoptera: Braconidae) (Graham, 1969). Here we newly report Neodiprion xianyunicus Xiao et Zhou and Diprionidae sp. (Hymenoptera: Symphyta).

Distribution. China (Sichuan, Yunnan, Tibet); Palearctic and Nearctic regions. This is the first record from the Oriental region.

\section{Dibrachys confusus (Girault, 1916), new record to China}

Figs 19-22

Coelopisthia confusus Girault, 1916a: 246.

Dibrachys confusus (Girault): Peck 1951: 554; Grissell 1974: 318; Burks 1979: 828.

Diagnosis. Body slightly slender (Figs 19, 20), about $2.6 \mathrm{~mm}$. Head in frontal view (Fig. 21) $1.15 \times$ as wide as high; antennal scrobe extending upwards and not reaching anterior ocellus; antennal insertion slightly above lower ocular line; lower face flat; clypeus with transverse striation and lower margin protruding, emarginate with two blunt teeth. Antennal scape slightly shorter than eye height $(0.91 \times)$ but reaching lower margin of anterior ocellus; length of pedicel and flagellum combined shorter than head width; anelli transverse; each funicular segment slightly longer than its broad respectively. Head in dorsal view with width $2 \times$ length; eye length $1.87 \times$ temple length; POL 1.46× OOL. Mesosoma $1.43 \times$ as long as broad, mesoscutum with regular sculpture. Propodeum with median carina complete (Fig. 22), plicae complete and parallel anteriorly. Fore wing $2.38 \times$ as long as broad ; submarginal vein $2.37 \times$ as long as marginal vein; marginal vein $1.72 \times$ as long as postmarginal vein; stigmal vein as long as postmarginal vein. Gaster $2 \times$ as long as broad, narrower than thorax width.

Material examined. China: $3 q$, Beijing: Yuanmingyuan Imperial Garden, 2.VI.1984, ex. larvae of Lymantria dispar (L.), leg. Ding-Xi Liao.

Hosts. De Santis (1983) reported Megachile rotundata (Fabricius) (Hymenoptera: Megachilidae) as a host and here we record the larvae of Lymantria dispar (L.)(Lepidoptera: Lymantriidae).

Distribution. China (Beijing); Palearctic, Nearctic and Neotropical regions. 

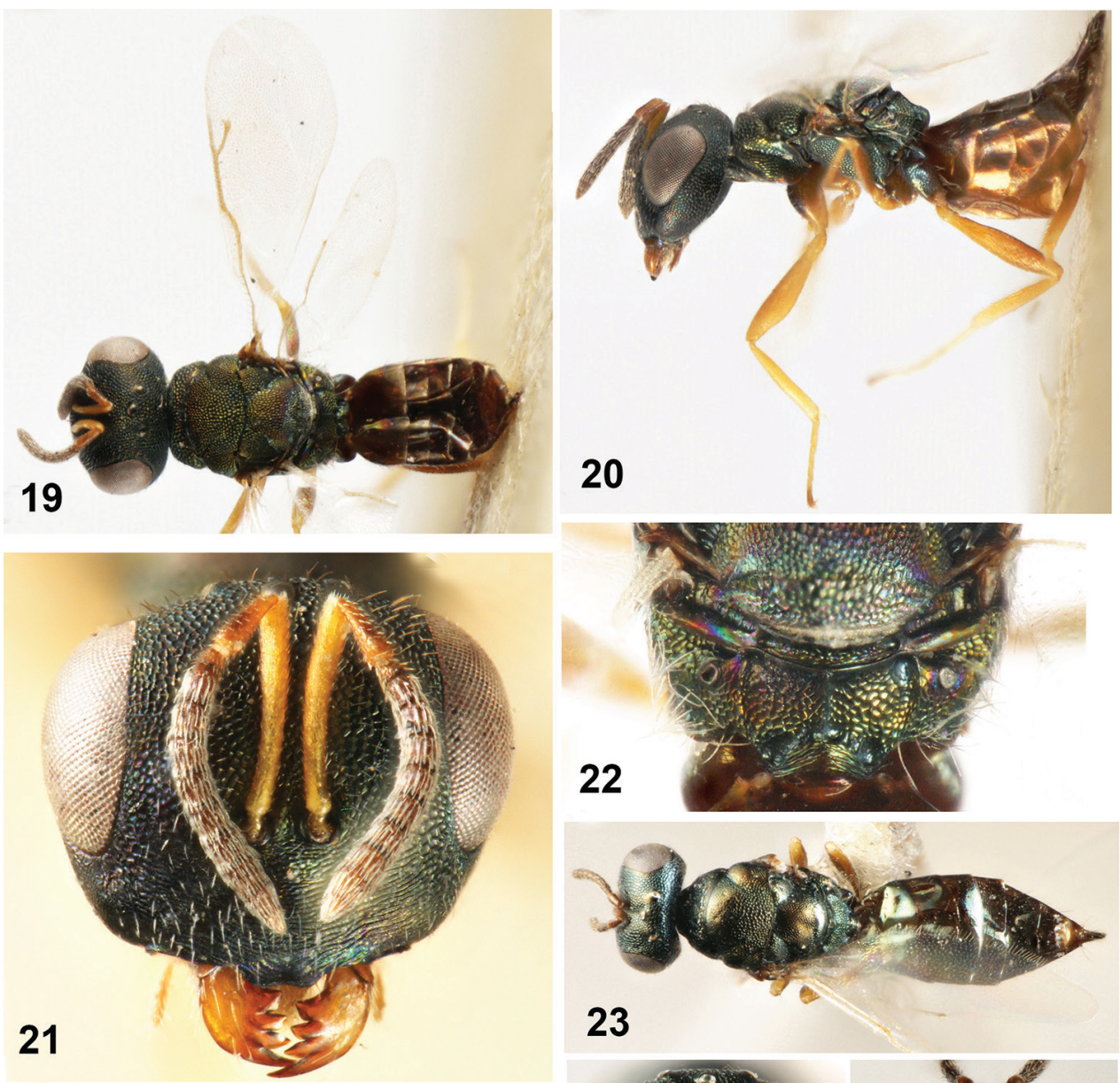

\section{3}
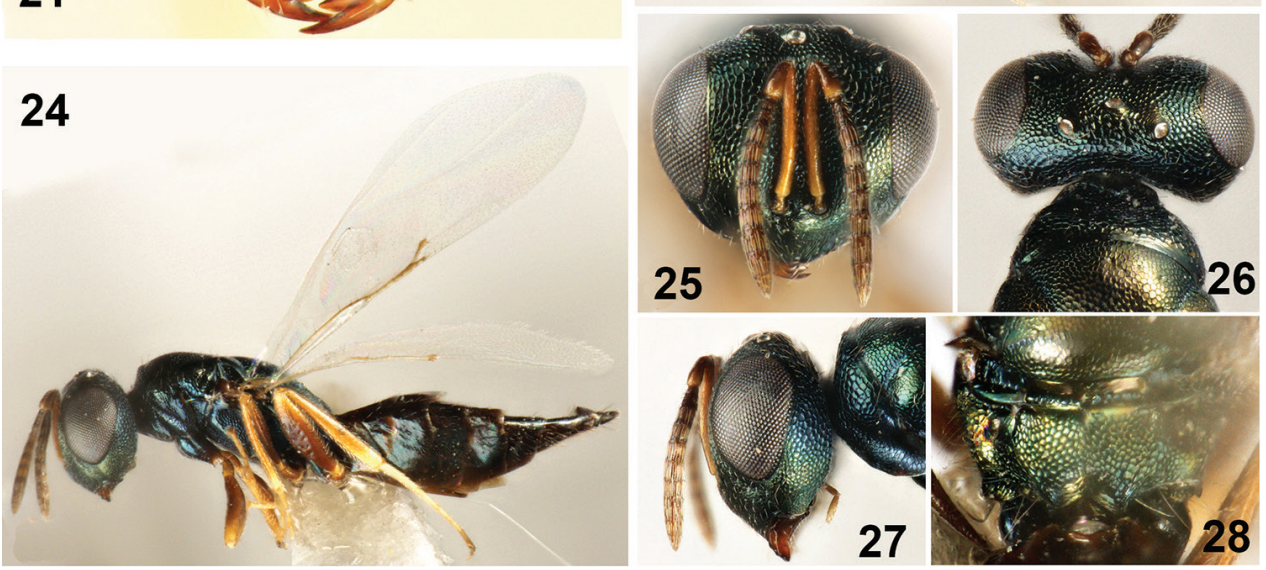

Figures 19-28. 19-22 Dibrachys confusus (Girault, 1916) 19 Body in dorsal view 20 Body in lateral view 21 Head in frontal view 22 Propodeum 23-28 Dibrachys golmudica sp. n., female holotype $\mathbf{2 3}$ Body in dorsal view $\mathbf{2 4}$ Body in lateral view $\mathbf{2 5}$ Head in frontal view $\mathbf{2 6}$ Head in dorsal view $\mathbf{2 7}$ Head in lateral view $\mathbf{2 8}$ Propodeum. 


\section{Dibrachys golmudica Jiao \& Xiao, sp. n.}

http://zoobank.org/F39A82B6-44C1-4E9A-9D23-B4462E870754

Figs 23-28

Diagnosis. The new species belongs to Dibrachys s. str., and the noticeable differences with other species of the subgenus by the following characters: in female, antennae with three anelli; the postmarginal vein being distinctly shorter than the stigmal vein $(0.5 \times)$, and gaster being $2.5 \times$ as long as broad.

Description. Holotype. Female. Body length $2.2 \mathrm{~mm}$ (Figs 23, 24). Head and mesosoma black with bronze luster and metallic reflection. Gaster dark brown with metallic reflection basally. Antennal scape yellowish brown to light brown from base to apex, flagellum dark brown; legs yellowish brown except coxae concolorous with body and femora light brown; fore wing hyaline, without infumation, venation yellowish brown or yellowish.

Head in frontal view (Fig. 25) $1.24 \times$ as wide as high; eyes with inner margins parallel, eye height $0.62 \times$ head height, eyes separated by $1.26 \times$ their height; lower face with weak striation, upper face with obvious regular reticulation; antennal scrobe deep, not reaching anterior ocellus. Antennal insertion on lower ocular line, distance from upper margin of torulus to lower margin of anterior ocellus $2.54 \times$ distance from lower margin of torulus to lower margin of clypeus; clypeus with longitudinal striation on both sides, lower margin slightly protruded, emarginate in middle with two obtuse teeth; oral fossa $0.49 \times$ as wide as head. Head in lateral view (Fig. 27) with malar sulcus conspicuous, eye height $1.5 \times$ its broad and $2.83 \times$ malar space. Antennal scape length $0.91 \times$ eye height; length of flagellum and pedicel combined less than head width $(0.88 \times)$; pedicel in lateral view $2.3 \times$ as long as broad; antenna with 3 anelli, $\mathrm{Fu}_{1}$ and $\mathrm{Fu}_{2}$ distinctly transverse, $\mathrm{Fu}_{3}$ quadrate, $\mathrm{Fu}_{1}$ to $\mathrm{Fu}_{3}$ combined $0.78 \times$ as long as pedicel; $\mathrm{Fu}_{4}$ longer than broad, $\mathrm{Fu}_{5}$ quadrate; each funicular segment with one row of sensilla; setae on funicle all decumbent; clava not distinctly clavate, $3.4 \times$ as long as broad, micropilosity limited to apex of third clava segment. Head in dorsal view (Fig. 26), 2x as wide as long; vertex convex, sculpture on vertex slightly smaller than sculpture on frons; occipital carina distinct; eye length $2.5 \times$ temple length; POL $2.11 \times$ OOL.

Head $1.24 \times$ as broad as thorax. Mesosoma $1.6 \times$ as long as broad. Pronotum $0.65 \times$ as broad as mesoscutum, collar rounded, posterior band smooth. Mesoscutum 1.57x as broad as long, with regular reticulation, in anterior half weakly reticulate and posterior half with deep reticulation; notauli distinct but not complete. Scutellum convex, $1.07 \times$ as broad as long, frenal line absent; reticulation smaller than on mesoscutum, but regular and shallow. Propodeum medially $1 / 2$ as long as scutellum, with fine, deep, dense reticulation; plica weak (Fig. 28), only visible basally and separated by $2 \times$ medial length of propodeum; median carina incomplete; propodeum with short, slightly convex nucha having transverse striation; propodeal spiracles elongate, $2.67 \times$ as long as broad. Fore wing $2.16 \times$ as long as broad, without marginal fringe; setae pale, inconspicuous; basal vein and basal cell bare, upper surface of costal cell bare, lower surface with one complete row of setae and distally with some scattered setae; submarginal 
vein $2.75 \times$ as long as marginal vein, marginal vein $2.63 \times$ as long as stigmal vein, postmarginal vein shorter than stigmal vein (at most $0.5 \times$ ); stigmal vein slightly curved.

Gaster spindle-shaped with apex pointed (Fig. 23), 2.5x as long as broad; as wide as thorax; $\mathrm{Gt}_{1}$ covering $1 / 4$ of gaster, with posterior margin cambered; tergites beyond $\mathrm{Gt}_{1}$ equal in length; ovipositor exserted.

Male. Head black except frons with yellowish-green, and antennae yellow; mesosoma black except thorax purplish laterally, legs yellow except coxae brown. Antennae with two distinctly transverse anelli, pedicel in lateral view $1.8 \times$ as long as broad, each funicular segment longer than broad; gaster oval, apex not pointed.

Material examined. Holotype. + , China: Qinghai: Golmud, Guolemude, $2880 \mathrm{~m}, 36.26^{\circ} \mathrm{N}, 94.53^{\circ} \mathrm{E}, 14 . \mathrm{IX} .2001$, leg. Chao-Dong Zhu. Paratype. 1 , , same

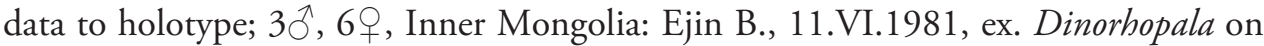
Populus diversifolia, leg. Hua-Qiang Shao.

Etymology. Named after the location where the holotype was collection.

Hosts. Specimens from Inner Mongolia were reared from Dinorhopala (Coleoptera: Curculionidae) on Populus diversifolia.

Distribution. China (Inner Mongolia, Qinghai).

\section{Dibrachys liaoi Jiao \& Xiao, sp. n.} http://zoobank.org/2418A0BD-799F-44D4-8A3B-BCCAB3FCF7C2 Figs 29-32

Diagnosis. The new species belongs to Dibrachys s. str., and the mainly differences with Dibrachys microgastri (Bouché) as follows: D. liaoi sp. n. slightly blue-greenish, clypeal margin with two sharp teeth, $\mathrm{Fu}_{1}$ to $\mathrm{Fu}_{4}$ length slight longer than its width respectively, $\mathrm{Fu}_{5}$ and $\mathrm{Fu}_{6}$ quadrate, gaster $1.8 \times$ as long as broad; but in $D$. microgastri (Bouché), body yellow-green, clypeal margin with two blunt teeth, $\mathrm{Fu}_{1}$ to $\mathrm{Fu}_{5}$ quadrate, $\mathrm{Fu}_{6}$ transverse, gaster $2 \times$ as long as broad.

Description. Holotype. Female. Body (Figs 29, 30) length $2.2 \mathrm{~mm}$. Head and mesosoma dark green, with metallic reflection; gaster brown and with metallic reflection basally. Antennae dark brown except scape and pedicel yellowish brown; mandible brown; legs yellowish brown except coxae brown; fore wing slightly infumate, wing venation yellowish brown.

Head in frontal view (Fig. 31), width 1.24x height; frons with dense reticulation; lower face flat, reticulation on lower face same as that on frons; eye height $0.7 \times$ head height, eyes separated by $1.09 \times$ eye height; antennal scrobe deep, extending upwards but not reaching anterior ocellus. Antennal insertion on lower ocular line, distance from upper margin of torulus to lower margin of anterior ocellus $2.35 \times$ distance from lower margin of torulus to clypeal margin; clypeus with longitudinal sculpture, only small area smooth; clypeal margin protruded, emarginate in middle with two sharp teeth; oral fossa width $0.46 \times$ head width. Head in lateral view, malar sulcus inconspicuous, eye height $3.3 \times$ malar space. Antennal scape $0.81 \times$ as long as eye height, not reaching lower margin 

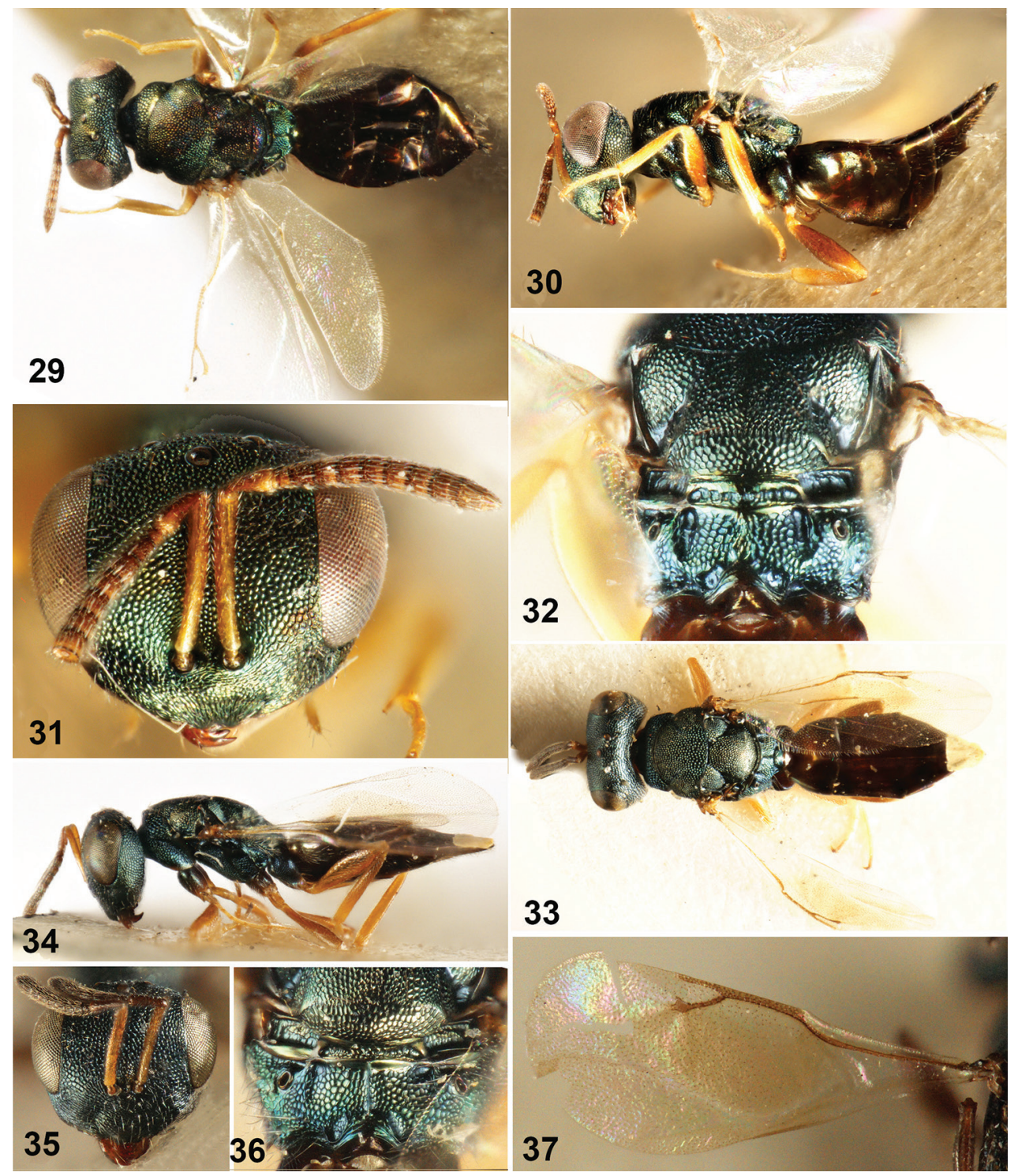

33

Figures 29-37. 29-32 Dibrachys liaoi sp. n., female holotype 29 Body in dorsal view 30 Body in lateral view 31 Head in frontal view 32 Propodeum 33-37 Dibrachys maculipennis Szelényi 33 Body in dorsal view $\mathbf{3 4}$ Body in lateral view $\mathbf{3 5}$ Head in frontal view $\mathbf{3 6}$ Propodeum $\mathbf{3 7}$ Fore wing.

of anterior ocellus; length of pedicel and flagellum combined shorter than head width $(0.84 \times)$; pedicel in lateral view $2.6 \times$ as long as broad; anelli transverse; $\mathrm{Fu}_{1}$ to $\mathrm{Fu}_{4}$ slightly longer than broad respectively, $\mathrm{Fu}_{5}$ and $\mathrm{Fu}_{6}$ quadrate; each funicular segment with one row of longitudinal sensilla; clava slightly clavate, $2.43 \times$ as long as broad, micropilosity only limited to apex of third clava segment. Head in dorsal view $1.89 \times$ as wide as long; vertex convex, occipital carina strong; eye length $2 \times$ temple length; POL 1.64× OOL. 
Head $1.31 \times$ as broad as thorax. Mesosoma $1.38 \times$ as long as broad. Pronotum with raised reticulation, pronotal collar slightly narrower than mesoscutum $(0.86 \times)$; middle length of pronotum almost $1 / 9$ as long as length of mesoscutum; collar not margined anteriorly, posterior margin of collar with a smooth band. Mesoscutum 1.86x as broad as long, with regular and dense reticulation; notauli incomplete and unconspicuous. Scutellum convex, $1.09 \times$ as broad as long, frenal line absent; reticulation same as on mesoscutum but slightly large on posterior part of scutellum. Propodeum (Fig. 32) medially $1 / 2$ as long as scutellum; plica complete; median carina incomplete, occasionally with one or two short longitudinal ridge which interrupted in the middle; nucha short and smooth, separated with middle part of propodeum by a transverse shallow depression; spiracles elongate, $2 \times$ as long as broad, separated by the width of spiracles from hind margin of metanotum; area below spiracles with finely reticulation. Fore wing $2.25 \times$ as long as broad, without marginal fringe; basal vein with sparse setae, basal cell bare; speculum only stretched to $1 / 3$ base of marginal vein; upper surface of costal cell bare, lower surface with a one complete row of setae and distal $1 / 3$ with some scattered setae; submarginal vein $2.33 \times$ as long as marginal vein; marginal vein $1.67 \times$ as long as postmarginal vein; stigmal vein as long as postmarginal vein, slightly curved.

Petiole invisible dorsally. Gaster (Fig. 29) long ovate, $1.8 \times$ as long as broad, 1.3× as broad as thorax width; surface of each tergite coriaceous; $\mathrm{Gt}_{1}$ covering 1/3 length of gaster, posterior margin of $\mathrm{Gt}_{1}$ cambered, median with an obvious hollow; following tergites with posterior margin straight; gaster terminal acute.

Male. Body length $2.1 \mathrm{~mm}$; head and thorax blue-green; antenna light brownish except clava slightly dark, other segments yellow; legs yellow to yellowish brown except coxae concolorous with body; fore wing yellowish brown; gaster brown, with a yellow transverse bright ribbon at $1 / 3$ base of gaster.

Material examined. Holotype: China: + , Beijing: Miyun Reservoir, $40.29^{\circ} \mathrm{N}$, $116.50^{\circ} \mathrm{E}, 18 . \mathrm{VII} .1983$, ex. pupae of Dendrolimus tabulaeformis, leg. Ju-Wen Wu. Paratypes: China: $1 \hat{\jmath}, 2 q$, same data as holotype; $2+$, Beijing: Miyun Reservoir, 20.VII.1983, ex. pupae of Dendrolimus tabulaeformis, leg. Ju-Wen Wu; 5, Beijing: Huairou, 15.VI.1982, ex. Illiberis pruni, leg. Mr. Jin; 1우, Beijing: Songshan, 26.VIII.1984, ex. Illiberis pruni; 4우 Beijing: Changping, 15.VI.1981, ex. Locastra muscosalis, leg. Zhen-Hua Liu; 1으, Beijing: Yuanmingyuan Imperial Garden, 18.VII.1984, ex. larvae of Lymantria dispar, leg. Mu-Zong Cheng; 69, Beijing: Yuanmingyuan Imperial Garden, 2.VI.1984, ex. larvae of Lymantria dispar, leg. Ding-Xi Liao; 40, 5ㅇ, Beijing: Mentougou, late July of 1983, ex. Prothesia similes xanthocam$p a$, leg. Sui-Hua Zhao; 1ㅇ, Beijing: Qingbaichang, leg. Ding-Xi Liao.

Etymology. In memory of professor Ding-xi Liao in China.

Hosts. Larvae of Illiberis pruni Dyar, Illiberis nigra Leech (Lepidoptera: Zygaenidae), Lymantria dispar (L.) (Lepidoptera: Noctuoidea) and Porthesia similis (Fueszly) (Lepidoptera: Lymantridae), pupae of Dendrolimus tabulaeformis Tsai et Liu, Dendrolimus superans (Butler) (Lepidoptera: Lasiocampidae), Illiberis ulmivora Graeser, Pseudopanolis flavimacula Inaba (Lepidoptera: Noctuidae), Rogas dendrolimi (Matsumura) (Hymenoptera: Braconidae) and Tenthredinidae sp..

Distribution. China (Liaoning, Beijing, Hebei, Shanxi, Shandong, Gansu, Qinghai). 


\section{Dibrachys maculipennis Szelényi, 1957, new record to China}

Figs 33-37

Dibrachys maculipennis Szelényi, 1957: 301, 307.

Diagnosis. Body slender (Figs 33, 34), length 2.2-2.3 mm; gaster spindle. Head in frontal view (Fig. 35), 1.13 $\times$ as wide as high; antennal scrobe very shallow, extending upwards but not reaching anterior ocellus; antennal insertion slightly above lower ocular line; lower face flat; clypeus with transverse striation and lower margin slightly protruding with two blunt teeth. Antennal scape as long as eye height, reaching lower margin of anterior ocellus; length of pedicel and flagellum combined slightly shorter than head width $(0.95 \times)$; anelli transverse; $\mathrm{Fu}_{1}$ to $\mathrm{Fu}_{3}$ slightly long than broad respectively, $\mathrm{Fu}_{4}$ and $\mathrm{Fu}_{5}$ quadrate, $\mathrm{Fu}_{6}$ slightly transverse; clava slightly clavate, $2 \times$ as long as broad. Head in dorsal view, $2 \times$ as wide as long; occipital carina strong; POL $1.5 \times$ OOL. Mesosoma $1.6 \times$ as long as broad, with regular reticulation. Propodeum (Fig. 36) with median carina incomplete; plicae distinct anteriorly. Fore wing (Fig. 37) with a yellowish-brown infumation behind marginal vein; submarginal vein $2 \times$ as long as marginal vein, marginal vein $1.94 \times$ as long as postmarginal vein, $1.5 \times$ as long as stigmal vein; stigma vein slightly longer than postmarginal vein $(1.1 \times)$. Gaster $2 \times$ as long as broad, $1.14 \times$ as broad as thorax width.

Material examined. China: 2q, Beijing, V1967; 1엉 Shaanxi: Hangzhou, X.1959, ex. Smerinthus planus Walker, leg. Zhe-Min Zheng; 1+, Zhejiang: Hangzhou, 7.VI.1972, ex. Apanteles baoris Wilkinson, leg. Ding-Xi Liao.

Hosts. Recorded hosts of the species were Megachile rotundata (Fabricius) (Hymenoptera: Megachilidae) (Peck 1969) and Hyphantria cunea (Drury) (Lepidoptera: Erebidae) (Dzhanokmen 1978). Here we newly report Smerinthus planus Walker (Lepidoptera: Sphingidae) and Apanteles baoris Wilkinson (Hymenopter: Braconidae).

Distribution. China (Beijing, Shaanxi, Zhejiang); Palearctic, Nearctic and Neotropic regions.

\section{Dibrachys microgastri (Bouché, 1834)}

Figs 38-41

Diplolepis microgastri Bouché, 1834: 168; neotype female in ZMH by Peters and Baur 2011: 12. Syntypes presumed lost (Graham 1969: 811). Möller 1886: 83; Vidal 2001, 7: 62 .

Dibrachys microgastri (Bouché) Peters \& Baur, 2011: 18; Vidal 2001: 62.

Synonymy: Pteromalus cavus Walker, 1835: 477-478; Pteromalus decedens Walker,

1835: 478; Pteromalus albinervis Ratzeburg, 1844: 199; Pteromalus boucheanus Ratzeburg, 1844: 196; Pteromalus tenuis Ratzeburg, 1844: 195; Pteromalus zelleri Ratzeburg, 1848: 190; Pteromalus vesparum Ratzeburg, 1852: 233; Cleonymus clisiocampae Fitch, 1856: 431-432; Pteromalus boarmiae Walker in Newman, 
1863: 8609, 8610; Cheiropachus nigro-cyaneus Norton, 1869: 327; Eupelmus cereanus Rondani, 1876: 38. 40; Pteromalus gelechiae Webster, 1883: 151; Pteromalus chionobae Howard, 1889: 1872, 1889; Arthrolytus apatelae Ashmead, 1893: 162; Arthrolytus pimplae Ashmead, 1894: 339; Trichomalus truyilloi Blanchard, 1938: 178; Tritneptis elegans Szelényi, 1981: 400.

Diagnosis. Body slender (Figs 38, 39), length $1.8-2.5 \mathrm{~mm}$; gaster long ovate, spindleshaped. Head in frontal view (Fig. 40), width 1.21× height; antennal scrobe extending upwards but not reaching anterior ocellus; antennal insertion placed on lower ocular line; lower face at least slightly convex; sculpture on face larger than on vertex; clypeus with longitudinal striation; lower margin of clypeus slightly protruded, emarginated and with two blunt teeth. Antennal scape slightly shorter than eye height; not reaching lower margin of anterior ocellus; length of pedicle and flagellum shorter than head width; anelli transverse; each funicular segment quadrate except $\mathrm{Fu}_{6}$ transverse; setae on antenna become an angle with antennal surface. Mesosoma $1.43 \times$ as long as broad; mid lobe of mesoscutum with coarse sculpture. Propodeum with complete plicae and weak median carina. Fore wing (Fig. 41) $1.88 \times$ as long as broad; submarginal vein $2 \times$ as long as marginal vein, marginal vein $1.9-2.5 \times$ postmarginal vein, postmarginal vein shorter or as most as long as stigmal vein; stigmal vein straight. Gaster $2 \times$ as long as broad, slightly broader than thorax width.

Material examined. China: $3 \widehat{\partial}, 7$, Heilongjiang: Hailin, VI.1975, ex. pupae of Atractodes sp., leg. Gui-You Zhang; 2仓, 1우, Heilongjiang: Yichun, 3.VII.1972, ex. Tachinidae sp. on Tortricidae sp., leg. Ding-Xi Liao; $1 \hat{O}^{\lambda}, 8+$ Heilongjiang: Yichun, 13.VII.1962, ex. Tachinidae sp. on Ptycholomoides aeriferanus Herrich-Schaffer, leg. Ding-Xi Liao; 20̂, 69, Heilongjiang: Yichun, 18.IX.1975, ex. Ptycholomoides aeriferanus Herrich-Schaffer, leg. You-Qiao Liu; 4ㅇ, Heilongjiang: Harbin, 3.VII.1962, ex. pupae of Yponomeuta padella Linnaeus, leg. Tai-Lu Chen; 59 , Heilongjiang: Harbin, 4.VII.1962, ex. pupae of flies, leg. Tai-Lu Chen; 10, 2 +, Heilongjiang: Harbin, 11.V.1978, ex. pupae of Anacampsis populella Clerck, leg. WenMin Chen; $2 \hat{\jmath}, 7$, Heilongjiang: Harbin, 11.IV.1978, ex. larvae of Aphididae

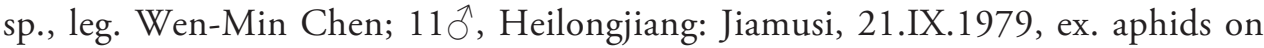
cabbagecabbage aphid, leg. Ding-Xi Liao; 1 $\delta, 8$ ㅇ,Heilongjiang: Mishan, VI.1963, ex. Pyrausta nubilalis (Hübner), leg. De-Yun Deng; 1 $\widehat{0}, 1$, Heilongjiang: Dailing, 18.IX.1975, ex. Rhyacionia buoliana, leg. Ding-Xi Liao; 2ㅇ, Jilin: Siping, VII.1980, ex. Coleophoridae sp., leg. Yu-Ying Qiu; 5, Liaoning: Liaoyang, 19.VI.1980, ex. larvae of Lymantria dispar L., leg. Yu-Bao Zhang and Gui-Zhi Zhang; 3ภ, 7 , Liaoning: Liaoyang, 17.VII.1979, ex. Musca domestica (Linnaeus,1758), leg. DingXi Liao; 1 9 , Liaoning: Liaoyang, 10.VI.1979, ex. pupae of Cnidocampa flavescens (Walker), leg. Yu-Bao Zhang; 5 9 , Liaoning: Jinzhou, vi.1970, ex. Nephoteryx pirivorella Matsumura, leg. Bin Liu; 1ठ, 1ㅇ, Liaoning: Shenyang, 11.VII.1978, ex.

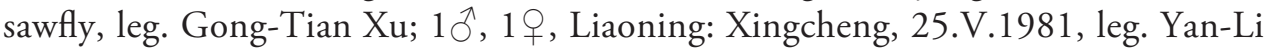
Zhao; 49, Liaoning: Suizhong, 13.IX.1973, ex. pupae of Tachinidae sp., leg. ShuHai Wang; 59, Liaoning: Liaoyang, Yuejiadadui, 1979, ex. pupae of Lymantria 

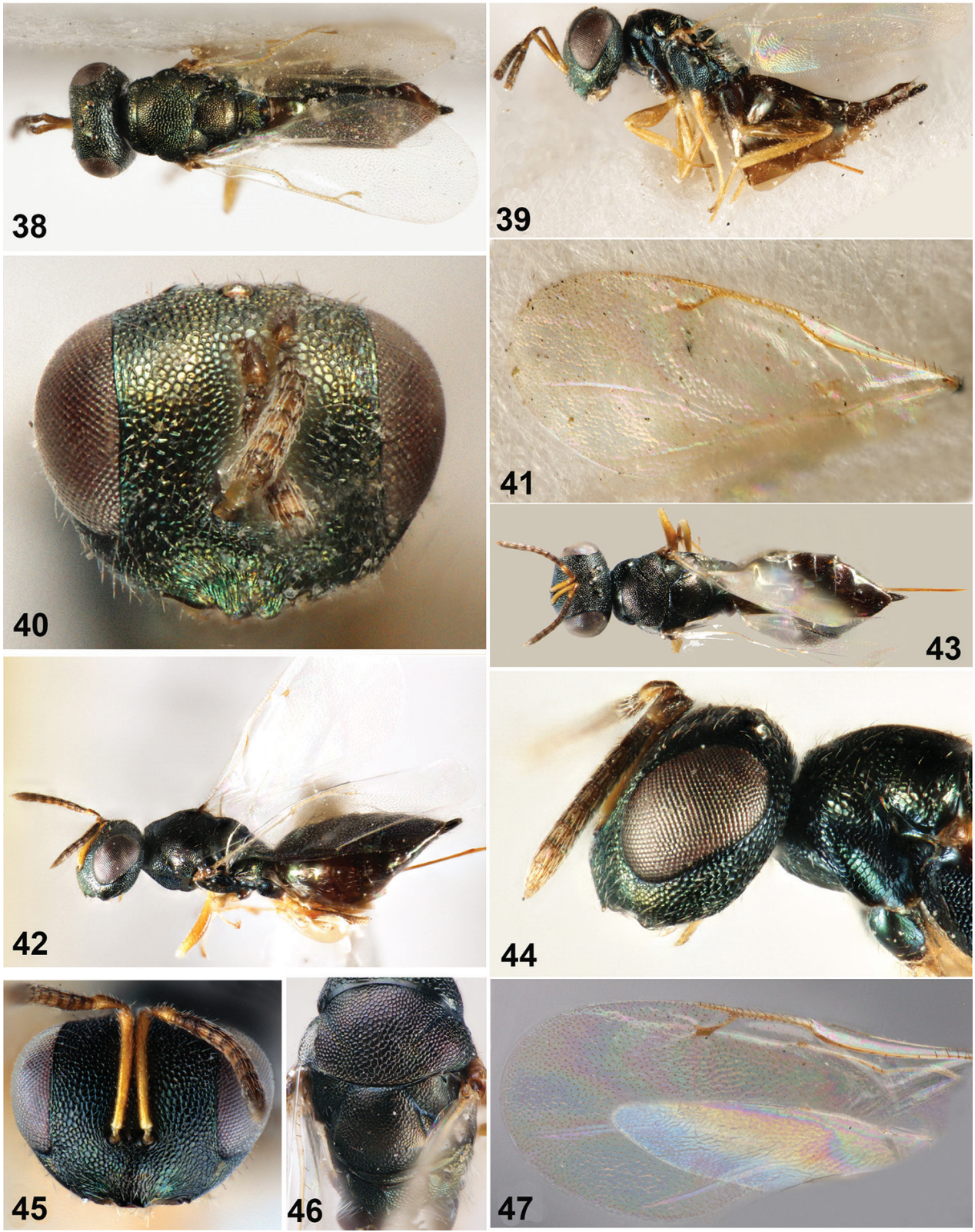

Figures 38-47. 38-4I Dibrachys microgastri (Bouché) 38 Body in dorsal view 39 Body in lateral view 40 Head in frontal view 4 I Fore wing 42-47 Dibrachys qinghaiensis sp. n., female holotype $\mathbf{4 2}$ Body in lateral view 43 Body in dorsal view 44 Head in lateral view 45 Head in frontal view 46 Mesoscutum 47 Fore wing.

dispar (L.) from Populus sp., leg. Yu-bao Zhang \& Gui-Zhi Zhang; 1+, Liaoning: Liaoyang, Beiling, 5.IX.1978, ex. Lymantria dispar (L.), leg. Gong-Tian Xu; 1 , Liaoning: Fuxian, 25.VI.1976, ex. Tortricidae sp., leg. Ding-Xi Liao; 3 , , Liaon- 
ing: Siping, VI.1989, ex. Yponomeutidae sp., leg. Gui-You Zhang; 8q, Liaoning: Fusong, IX.1953, ex. eggs of Dendrolimus sp.; 2옹 Inner Mongolia: Urad Middle Banner, 17.VII.1980, ex. Anacampsis Populella Clerck, leg. Xu-Chang Huang; $3 \widehat{\partial}$, Inner Mongolia: Horinger, 4.VIII.1981, ex. Malacosoma sp., leg. Qiang-Hua Shao; $10^{\lambda}, 2$, Inner Mongolia: Baotou, 19.IX.1989, ex. pupae of gelechiid moth,

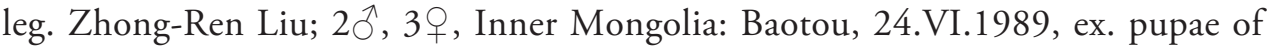
ichneumon, leg. Zhong-Ren Liu; 19, Inner Mongolia: Baotou, 28.vii.1985, ex. Scolytidae sp., Zhong-Ren Liu; 3 $\bigcirc^{\lambda}, 7$, , Beijing, vii.1986, ex. pupae of Tachinidae sp., leg. Da-Wei Huang; 1ð, 9ㅇ, Beijing, 21.VIII.1962, ex. Tortricid, leg. DingXi Liao; 5 , Beijing: Xijiao, 20.IX.1957, ex. pupae of Stilprotia salicis, leg. Tai-Lu Chen; 1 q, Beijing: Miyun, 17.VI.1984, ex. Dendrolimus tabulaeformis, leg. Da-Wei Huang; 2今, 6q, Beijing: Daxing, 1963, ex. obsolete honeycomb, leg. Zong-You $\mathrm{Xu} ; 2$, Beijing: Yuanmingyuan Imperial Garden, 25.vii.1984, ex. larvae of Lymantria dispar, leg. Mu-Zong Cheng; 4, Hebei: Zhangbei, VII-XII.1983, ex. Stilpno-

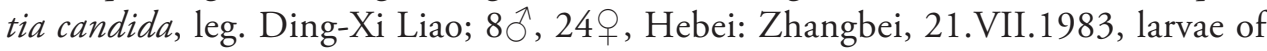
Stilpnotia candida, leg. Xing-Jun Li; 9 , Hebei: Zhangbei, vii.1983, ex. Lymantridae sp., leg. Xing-Jun Li; $1 \delta^{\lambda}, 5$, Hebei: Zhangbei, ex. pupae of Gypsonoma minutara, leg. Jun-Rong Dai; 1 , Hebei: Fengning, 20.v.1992, ex. Rogas dendrolimi (Matsumura), leg. Da-Zhou Wang; 20, 3q, Shanxi: Taiyuan, 6.V.1991, ex. Eulecanium gigantean, leg. Hui-Di Zhang; 2q, Shanxi: Taigu, 8.VII.1979, ex. pupae of Yponomeutidae sp., leg. Zhan-Gui Li; 10, 2o, Shanxi: Taiyuan, 19.vi.1990, ex. pupae of Yponomeuta polystinellus Felder, leg. Da-Wei Huang; 1 $\delta^{\lambda}, 1$, Shanxi: Taiyuan, iv.1980, ex. pupae of Ancylis sativa Liu, leg. Ci Yu; 3 \%, Shanxi: Pingshun, 10.VIII.1978, ex. Pinus tabuliformis Carrière; $1{ }^{\lambda}, 1$, , Shanxi: Taigu, 8.VII.1979, ex. pupae of Galleria mellonella, leg. Zhan-Gui Li; 3 , , Shanxi: Taigu, 15.VI.1979, ex. larvae of Illiberis nigra Leech, leg. Zhan-Gui Li; 4ㅇ, Shanxi: Taigu, VII.1979, ex. Illiberis nigra Leech, leg. Zhan-Gui Li; 19, Shanxi: Taigu, VII.1979, ex. Lithocolletis ringoniella Mats., leg. Zhan-Gui Li; 2 \%, Shanxi: Shuoxian, 24.V.1984, ex. Braconidae on Coccinella septempunctata, leg.Yu-Zhi Niu; $3 \hat{\jmath}$, 6q, Shanxi: Shuoxian, 3-16.VI.1984, ex. Braconidae sp. on Anacampsis Populella Clerck, leg.Yu-Zhi

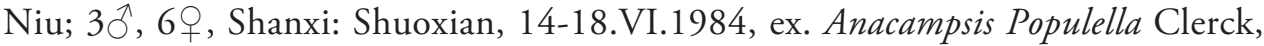
leg. Yu-Zhi Niu; 1ð̄, 2q, Shanxi: Shuoxian, 20.VI.1983, ex. Anacampsis Populella Clerck, leg.Yu-Zhi Niu; 1ð̃, 7q, Shanxi: Shuoxian, V-VII.1984, ex. Tachinidae sp. on Anacampsis Populella Clerck, leg.Yu-Zhi Niu; 19, Shangdong: Weihai, 3.VI.1958, leg. Jin-Long Mao; 1ㅇ, Shangdong: Fushan, 26.X.1958, leg. Jin-Long Mao; 10̂, 4ㅇ, Henan: Anyang, 20.V.1956, ex. Pectinophora gossypiella (Saunders),

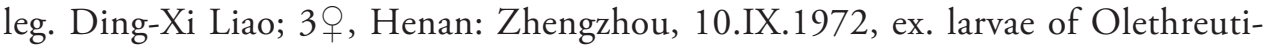
dae sp., leg. Ding-Xi Liao; 1 9 , Shaanxi: Xianyang, 6.III.1975, ex. pupae of Earias cupreoviridis Walker, leg. Ding-Xi Liao; 20, 69, Ningxia: Luhuatai, 29.V.1982, ex. Ypsolopha vittellus (Linnaeus), leg. Ding-Xi Liao; 39 , Ningxia: ZhongweisShapotou, 15.VI.1981, leg. Ding-Xi Liao; 3으. Ningxia: Yinchuang, 12.VI.1974, ex. pupae of Syrphidae sp. on Ulmus pumila L.; 1ठ, 99 , Gansu: Pingliang, VII.1966, ex. Tachinidae sp. \& Illiberis pruni, leg. Shou-Min Liu; $3912{ }^{\top}$, Gansu: Pingli- 


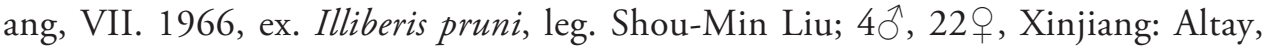
VI.1979, ex. larvae of Gelechia pinguinella Trietschke, leg. Jun-Wen Xia; 5 , , Xinjiang: Korla, collecting time unknown, ex. eggs of Macroglossum corythus luteata (Butler), leg. Tai-Lu Chen; 3 , Xinjiang: Urumchi, 12.VII.1980, ex. pest on Salix sp., leg. Jiu-Xiong Bai; $1 \hat{\jmath}$, 5q, Jiangsu: Nanjing, 4.VII.1963, leg. Ding-Xi Liao; 2へ, 5q, Shanghai: Pudong New District, III.1972, ex. cottonseed; 4q, Shanghai: Minhang, XII.1979, ex. Apanteles glomeratus (L.), leg. Ji-Long He; 6ㅇ, Anhui: Dangshan, 7.XI.1975, ex. Pyrausta nubilalis (Hubern) \& Chilo infuscatellus (Snellen), leg. Ding-Xi Liao; 129, Anhui:Huangfu Mountain, 19.VI1965, ex. larvae of Lepidoptera, leg. Ding-Xi Liao; 1へ, 4ㅇ, Zhejiang: Hangzhou, X.1954, ex. Pectinophora gossypiella (Saunders); 20, 69, Zhejiang: Hangzhou, i.1963, leg. Ding-Xi Liao; 5 $\widehat{\text { O }}$ 2 9 , Zhejiang: Hangzhou, I.1963, ex. Pectinophora gossypiella (Saunders),

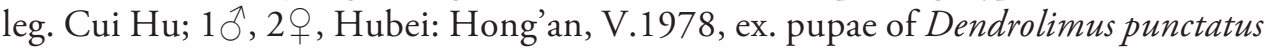
Walker, leg. Ding-Xi Liao; 69, Hunan: Changsha, 20.III.1984, ex. Chilo suppressalis (Walker), leg. Ding-Xi Liao; 10, 9 9 , Hunan: Liuyang, 24.IX.1979, ex. eggs of Dendrolimus sp. , leg. Ding-Xi Liao; 1엉 Hunan, collecting time unknown, leg. Xin-Wang Tong; 1, Yunnan: Kunming, 17.V.1967, ex. larvae of Macrocentrus sp. leg. Jing-Liang Qi; 1언 Yunnan: Zhaotong, 5.IV.1973, ex. Chilo suppressalis (Walker), leg. Ding-Xi Liao; 1ð, 1 9 , Tibet: Lhasa, 3650m, 27.VIII.2001, leg. Chao-Dong Zhu. 2 +, Sk. Ahus, 15.IV.1979. leg. K. J. Hedqvist, Dibrachy cavus (Walker), det. K. J. Hedqvist; N. Zealand: 19, Lincoln, nr Christchurch RT., 1988, B.J. Donovan. Cult. Vespula gemanica, Dibrachys boarmiae (Walker), det. Z. Boucěk, 1988.

Hosts. Hosts of D. microgastri has been widely recorded, and the primary parasite has been recorded more than 240 species from 45 families of seven insects orders and also recorded two species of Arachnida (Noyes 2002). In our study, the species was parasitic on Coleoptera (Scolytidae sp.), Diptera (Tachinidae sp. on Tortricidae sp., Tachinidae sp. on Anacampsis Populella Clerck, pupae of Tachinidae sp. and Syrphidae sp. on Ulmus pumila L.), Hemiptera (aphids on cabbage), Hymenoptera (Apanteles glomeratus (L.), Braconidae sp. on Coccinella septempunctata, larvae of Macrocentrus sp., pupae of Gelis sp. and Lepidoptera (Chilo infuscatellus (Snellen), Chilo suppressalis (Walker), Lymantria dispar (L.), Malacosoma sp., Nephopteryx pirivorella (Matsumura), Pectinophora gossypeilla (Saunders), Ptycholomoides aeriferanus (Herrich-Schäffer), Pyrausta nubilalis (Hübner), Ypsolopha vittellus (Linnaeus), eggs of Dendrolimus sp., larvae of Gelechia pinguinella Trietschkeb and Olethreutidae sp., pupae of Anacampsis populella Clerck, pupae of Cnidocampa flavescens (Walker), pupae of Dendrolimus punctatus (Walker), pupae of Earias cupreoviridis Walker, pupae of Stilprotia salicis (L.), pupae of Yponomeuta padella Linnaeus and so on).

Distribution. China (Heilongjiang, Jilin, Liaoning, Inner Mongolia, Beijing, Hebei, Shanxi, Shangdong, Henan, Shaanxi, Ningxia, Gansu, Xinjiang, Jiangsu, Shanghai, Anhui, Zhejiang, Hubei, Hunan, Yunnan, Tibet); widespread world-wide distribution (Noyes, 2016). 


\section{Dibrachys qinghaiensis Jiao \& Xiao, sp. n.}

http://zoobank.org/2C61C736-41D3-4EB0-8C0B-F3218A96B622

Figs $42-47$

Diagnosis. The new species belongs to Dibrachys s. str., and the mainly differences with Dibrachys microgastri (Bouché) are as follows: antenna of D. qinghaiensis sp. n. slender, each funicular segment at least slightly longer than its broad; antennal scape as long as eye height, and nearly reaching lower margin of anterior ocellus; but D. microgastri (Bouché) at least with several transverse funicular segment in distal of antenna, antennal scape distinctly shorter than eye height, and not reaching lower margin of anterior ocellus.

Description. Holotype. Female. Body (Figs 42, 43) length $2.2 \mathrm{~mm}$. Head and mesosoma dark green, with brown gloss and metallic reflection; gaster dark brown. Antenna with scape and pedicel yellowish brown, but brownish in dorsum, other segments of antenna dark brown; mandible yellowish brown and margin of teeth brownish; legs yellowish brown except coxae concolorous with body; fore wing hyaline, wing venation light yellow.

Head in frontal view, 1.27x as wide as high (Fig. 45); frons with very dense reticulation; antennal scrobe with rather large reticulation; lower face flat, with densely transverse striation except lower edge of clypeus smooth; eye height $0.64 \times$ head height, eyes separated by $1.23 \times$ eye height; scrobe shallow, extending upwards but not reaching anterior ocellus. Antennal insertion slightly above lower ocular line, distance from upper margin of torulus to anterior ocellus $1.58 \times$ distance from lower margin of torulus to lower margin of clypeus; clypeal margin protruded, emarginate in middle with two small blunt teeth; oral fossa width $0.59 \times$ head width. Head in lateral view (Fig. 44) with malar sulcus inconspicuous, eye height $2.2 \times$ malar space. Antennal scape as long as eye height, nearly reaching lower margin of anterior ocellus; length of pedicel and flagellum combined shorter than head width $(0.85 \times)$; pedicel in lateral view $3 \times$ as long as broad; anelli transverse; each funicular segment slightly longer than broad; each funicular segment with one row of longitudinal sensilla; clava slightly clavate, $2.57 \times$ as long as broad, micropilosity only limited to apex of third clava segment. Head in dorsal view $2 \times$ as wide as long, vertex convex, occipital carina strong; eye length $1.87 \times$ temple; POL $1.49 \times$ OOL.

Head width $1.31 \times$ as broad as thorax. Mesosoma $1.43 \times$ as long as broad. Pronotum with coarse reticulation, $0.87 \times$ as broad as thorax; pronotum with middle length $0.23 \times$ as long as mesoscutum, collar subhorizontal and not margined, posterior margin smooth. Mesoscutum $2 \times$ as broad as long, with finely dense reticulation (Fig. 46), posterior reticulation larger than anterior reticulation; notauli incomplete but conspicuous anteriorly. Scutellum flat, as long as broad, frenal line absent; finely reticulate. Propodeum medially $0.43 \times$ as long as scutellum, central area flat and with regular reticulation; plicae complete and parallel anteriorly, separated by $1.82 \times$ medial length of propodeum; median carina complete; propodeum with short, convex nucha; spiracles elongate, $2 \times$ as long as broad, separated by the width of spiracles from hind margin of metanotum; area below spiracles with conspicuous and deep reticulation. Fore wing (Fig. 47) $2.38 \times$ as long as broad, without marginal fringe; upper surface densely pubes- 
cent; basal vein with sparse setae, basal cell bare, speculum only stretched to the base of marginal vein; upper surface of costal cell bare, lower surface with one complete row of setae and distal $1 / 3$ with two rows of short setae; submarginal vein $2.37 \times$ as long as marginal vein; marginal vein $2.64 \times$ as long as stigmal vein; postmarginal vein as long as marginal vein; stigmal vein slightly curved.

Petiole invisible dorsally. Gaster long ovate, $2 \times$ as long as broad; $0.89 \times$ as broad as thorax width, $1.33 \times$ as long as length of mesosoma; surface of each tergite coriaceous; $\mathrm{Gt}_{1}$ covering $1 / 3$ of gaster, posterior margin straight and with small hollow in middle; posterior margin of other tergites straight; terminal acute.

Male. Body length 1.3-1.9 mm, head and mesosoma black, with yellow-green shine; antennae yellow; legs yellow except coxae concolorous with body. Antennae with long hair, each funicular segment longer than its broad, with long hair on antenna. Gaster ovate, with an oval pale spot between $\mathrm{Gt}_{1}$ and $\mathrm{Gt}_{2}$.

Material examined. Holotype. China: 9 , Qinghai: Golmud, Guolemude, $2880 \mathrm{~m}$, $36.26^{\circ} \mathrm{N}, 94.53^{\circ} \mathrm{E}, 14 . \mathrm{IX} .2001$, leg. Chao-Dong Zhu. Paratype. China: $5{ }^{\lambda}$, 4 q, same data as holotype; 2ㅇ, Qinghai: Delhi, Baingoin, 2900m, 16.IX.2001, leg. Chao-Dong Zhu; 1q, Qinghai: Qilian, 2790m, 19.IX.2001, leg. Chao-Dong Zhu; 2q, Qinghai: Dulan, Xiangride, 10.VI.1997, leg. Chao-Dong Zhu; 4q, Qinghai: Xining, 3-4.VI.1997, leg. Chao-Dong Zhu; 2, Qinghai: Tongren, Mailin, 14.VI.1997, leg. Chao-Dong Zhu.

Etymology. The specific name is consist of the spelling of the type locality "qinghai" and the suffix "-ensis" represent source.

Hosts. Unknown.

Distribution. China (Qinghai, Yunnan).

\section{Acknowledgements}

Thanks are due to the Royal Society KC Wong Fellowship for offering a postdoctoral position in the Natural History Museum, London, which allowed the author examining the European specimens deposited in the NHM, the Naturalis, Leiden and the Bavarian State Collections of Zoology. Thanks are also especially to Dr. Zdenek Bouček and Dr. John Noyes for their help in accessing collections in NHM in 2001 and 2002. This work was supported by the Presidential Foundation of the CAS, Ministry of Science and Technology of China under Grant No. 2012FY111100 and the National Natural Science Foundation of China under Grant No. 31672338.

\section{References}

Ashmead WH (1893) Descriptions of new parasitic Hymenoptera bred by Prof. F.M. Webster. Bulletin of the Ohio Agricultural Experiment Station, Technical Series 1: 162.

Ashmead WH (1894) Descriptions of new parasitic Hymenoptera. Transactions of the American Entomological Society 21: 339. 
Blanchard EE (1938) Un nuevo enemigo de la oruga del duraznero. Revista Chilena de Historia Natural 41: 178.

Bouček Z (1965) A review of the Chalcidoid fauna of the Moldavian SSR, with descriptions of new species (Hymenoptera). Sborník Faunistickych Prací Entomologického Oddeleni Národního Musea v Praze 11: 5-37.

Bouček Z (1988) Australasian Chalcidoidea (Hymenoptera): a biosystematic revision of genera of fourteen families, with a reclassification of species. CAB International, Wallingford, $832 \mathrm{pp}$.

Bouček Z (1993) New taxa of North American Pteromalidae and Tetracampidae (Hymenoptera), with notes. Journal of Natural History 27: 1239-1313. https://doi. org/10.1080/00222939300770741

Bouché PF (1834) Naturgeschichte der Insekten, besonders in hinsicht ihrer ersten Zustande als Larven und Puppen. Berlin, 216 pp.

Burks BD (1979) Torymidae (Agaoninae) and all other families of Chalcidoidea (excluding Encyrtidae). In: Krombein KV, Hurd PD Jr, Smith DR, Burks BD (Eds) Catalog of Hymenoptera in America North of Mexico 1: 748-749, 768-889, 967-1043.

Dalla Torre KWvon (1898) Catalogus Hymenopterorum hucusque descriptorum systematicus et synonymicus. V. Chalcididae et Proctotrupidae. Lepzig, 598 pp.

De Santis L (1983) Catalogo de los Himenopteros Calcidoideos de America al Sur de los Estados Unidos - Primer Suplemento. Revista Peruana de Entomología 24 (1): 1-38.

Doganlar M (1987) Hypopygia of most Nearctic and Palaearctic species of Dibrachys Forster, key to most species of the genus and descriptions of three new species (Hymenoptera, Pteromalidae). Spixiana, München 10: 191-206.

Dzhanokmen KA (1978) Hymenoptera III. Chalcidoidea 5. Pteromalidae. Opredeliteli Nasekomikh Evropeyskoy Chasti SSR 3: 57-228.

Ferrière C, Faure JC (1925) Contribution à l'étude des chalcidiens parasites de l'Apanteles glomeratus L. Annales du Service des Epiphyties 11: 221-234.

Fitch A (1856) Report on the noxious, beneficial and other insects. Transactions of the New York State Agricultural Society 15: 431-432.

Förster A (1856) Hymenopterologische Studien. 2. Chalcidiae und Proctotrupii. Aachen, 152 pp.

Gahan AB (1913) A new genus and one new species of Chalcidoidea. Canadian Entomologist 45(6): 178-183. https://doi.org/10.4039/Ent45178-6

Gibson GAP, Huber JT, Woolley JB (1997) Annotated keys to the genera of Nearctic Chalcidoidea (Hymenoptera). National Research Council Research Press, Ottawa, 794 pp.

Girault AA (1916a) Descriptions of and observations on some chalcidoid Hymenoptera. Canadian Entomologist 48: 246. https://doi.org/10.4039/Ent48246-7

Girault AA (1916b) The North American species of Dibrachys (in the North American sense-Coelopisthoidea Gahan) with a note on Uriella Ashmead. Canadian Entomologist 48: 408-409. https://doi.org/10.4039/Ent48408-12

Graham MWRdV (1969) The Pteromalidae of north-western Europe (Hymenoptera: Chalcidoidea). Bulletin of the British Museum (Natural History) (Entomology), Supplement 16: 1-908.

Grissell EE (1974) A new Dibrachys with a key to the Nearctic species (Hymenoptera, Pteromalidae). Florida Entomologist 57: 313-320. https://doi.org/10.2307/3493271 
Howard LO (1889) [In: Scudder SH] The Hymenopterous parasites of North American Butterflies including a section upon the miscogasters by C.V. Riley. The Butterflies of the Eastern United States and Canada, with special reference to New England 3, 1872, 1889. Ishii T (1938) Chalcidoid-and proctotrypoid-wasps reared from Dendrolimus spectabilis Butler and D. albolineatus Matsumura and their insect parasites, with descriptions of three new species. Kontyû 12: 97-105.

Kamijo K (1982) Some pteromalids associate with forest pests in Japan, with descriptions of two new species. Kontyû 50: 67-75.

Liao DX, Li XL, Pang XF, Chen TL (1987) Economic Insect Fauna of China. Hymenoptera: Chalcidoidea. Science Press, Beijing, 34: 1-241.

Newman E (1863) Parasites and hyperparasites. Zoologist 21: 8609[257], 8610[258].

Möller GF (1886) Om kålfärillarvens parasiter. Entomologisk Tidskrift 7(2): 81-85.

Norton E (1869) American Hymenoptera. Transactions of the American Entomological Society 2: 327.

Noyes JS (2016) Universal Chalcidoidea Database. World Wide Web electronic publication. http://www.nhm.ac.uk/chalcidoids [accessed 12 September 2016]

Peck O (1951) Superfamily Chalcidoidea. In: Muesebeck CFW, Krombein KV, Townes HK (Eds) Hymenoptera of America north of Mexico-synoptic catalog.) Agriculture Monographs. U.S. Department of Agriculture 2: 410-594.

Peck O (1969) Chalcidoid (Hymenoptera) parasites of the alfalfa leaf-cutter bee, Megachile rotundata in Canada. Canadian Entomologist 101: 418-422. https://doi.org/10.4039/ Ent101418-4

Peters RS, Baur H (2011) A revision of the Dibrachys cavus species complex (Hymenoptera: Chalcidoidea, Pteromalidae). Zootaxa 2937: 1-30.

Ratzeburg JTC (1844) Die Ichneumonen der Forstinsekten in entomologischer und forstlicher Beziehung 1: 195-199.

Ratzeburg JTC (1848) Die Ichneumonen der Forstinsekten in entomologischer und forstlicher Beziehung 2: 190.

Ratzeburg JTC (1852) Die Ichneumonen der Forstinsekten in entomologischer und forstlicher Beziehung 3: 233.

Rondani C (1876) II nemico della tignuola della cera (Galleria cereana). Bollettino del Comizio Agrario Parmense 9: 38, 40.

Szelényi GV (1957) The hymenopterous parasites of Hyphantria cunea. Növenytermelés Kutato Intézet Évkónyve, Budapest 7: 295-312.

Szelényi G (1981) New genera and species of Pteromalidae (Hymenoptera: Chalcidoidea) collected in the Hungarian National Park, Hortobágy. Acta Zoologica Academiae Scientiarum Hungaricae 27: 400.

Thomson CG (1878) Hymenoptera Scandinaviae 5. Pteromalus (Svederus) continuation, 307 pp.

Trematerra P (1988) Arthropod antagonists of Pyralis farinalis (L.) (Lep., Pyralidae) and visitors of its larva shelters. Journal of Applied Entomology 105: 525-528. https://doi. org/10.1111/j.1439-0418.1988.tb00220.x

Vidal S (2001) Entomofauna Germanica. Band 4. Verzeichnis der Hautflügler Deutschalnds. Chalcidoidea. In: Dathe HH, Taeger A, Blank SM (Eds) Entomologische Nachrichten und Berichte Beiheft 7: 51-69. 
Viggiani G (1968) Si alcuni pteromalidi nuovi per l'entomofauna italiana, con interessante reperti biologici relative a specie del genre Dibrachys Forster. (XVI Ricerche sugli Hymenoptera Chalcidoidea.) Bollettino della Società. Entomologica Italiana 98: 112-115.

Walker F (1835) Monographia Chalciditum. (Continued.). Entomological Magazine 2: 476-502.

Wallace GE (1973) New Pteromalidae of the Dibrachys group (Hymenoptera: Chalcidoidea) with a key to genera. Annals of the Carnegie Museum 44(11): 171-181.

Webster FM (1883) Observations of the angoumois grain moth and its parasites. Report of the Illinois State Entomologist 12: 151.

Yang ZQ (1996) Parasitic Wasps on Bark Beetles in China. Science Press, Beijing, 363 pp.

Zerova MD, Tolkanits VI, Kotenko AG, Narolskiy NB, Fursov VI, Kononova SV, Nikitenko GN, Melika ZG, Sviridov SV (1992) Entomophages of pests of apple-trees in south-west region of the USSR. Naukova Dumka, Kiev, 276 pp. 